\title{
Optimal Decisions on Pension Plans in the Presence of Information Costs and Financial Literacy
}

\author{
Lorenzo Corsini ${ }^{*}$ and Luca Spataro ${ }^{\dagger}$
}

\begin{abstract}
Pension reforms are on the political agenda of many countries. Such reforms imply an increasing responsibility on individuals' side in building an efficient portfolio for retirement. In this paper we provide a model describing workers' choices on the allocation of retirement savings in presence of a) mandatory pension contribution; $b$ ) different pension plans; c) information costs and financial literacy investment decisions. In particular, we characterise the results from both a positive and normative standpoint, by highlighting the determinants of individuals' choice, with special focus on information costs, on the role of income and preferences, and by characterizing the optimal contribution rate to mandatory complementary pension plans. We also introduce endogenous financial literacy and analyse how its optimal level is determined and how it affects the decisions on pension plans.
\end{abstract}

J.E.L. Classification: D91, G11, G23, H5.

Keywords: Choice on pension plans; Optimal portfolio composition, Income inequality; Information costs; Investment in financial literacy.

\section{Introduction}

In recent decades pension systems of both developed and developing economies have been undergoing major reforms. Broadly speaking, such reforms rely on considerations which descend from the "optimal portfolio theory": in presence of assets whose risks are not completely correlated, differentiation of a portfolio over different assets can generate a more efficient investment than investing in a single asset.

Among the common features of the aforementioned reforms there is the possibility given to workers to choose how to invest a fixed part of their retirement savings between different opportunities. This is particularly true, for example, for Australia, Netherlands, Norway, Sweden and United Kingdom where a certain share of pension contributions can be directed towards alternative plans/schemes (usually called second pillar or complementary social security) but also for Argentina and Peru where mixed private/public schemes are present and workers are called to choose between them. Even New Zealand and US somehow fall in this category as the KiwiSavers and 401k plan, respectively, can be considered a possible option in which to invest retirement savings. Moreover, several countries undergoing important pension reforms (for example Hungary, Poland and Uruguay) have given workers the possibility to choose between the old and new system. Finally, on the extreme edge, there is Mexico whose whole pension system is run by private companies so that workers have directly to choose between alternative pension funds. In all these cases individuals have some degree of choice on how to invest part of their mandatory contribution.

A more detailed description of the pension systems of some of the countries mentioned above and of the dimension of the compulsory savings over which individuals have some degree of choice is summarized in Table 1. Given the working of the systems described in the table, we can say that, even if the alternatives provided to workers are different from country to country, there is a common trend in recent reforms that entails increasing responsibility on the workers' side in building up an adequate portfolio for facing retirement needs.

\footnotetext{
* Corresponding author. Dipartimento di Economia e Management, Università di Pisa. Via Ridolfi 10, 56124 Pisa, Italy. Tel: +39 0502216220 Fax: +39 0502216384. Email: lcorsini@ec.unipi.it.

† Dipartimento di Economia e Management, Università di Pisa (Italy) and CHILD. Email: 1.spataro@ec.unipi.it.
} 
Table 1: Complementary social security around the world: some examples of pension systems entailing freedom of choice and mandatory contribution

\begin{tabular}{|c|c|c|c|c|}
\hline & $\begin{array}{l}\text { Fixed amount of } \\
\text { mandatory } \\
\text { savings with } \\
\text { some degree of } \\
\text { choice (share of } \\
\text { total earnings) }\end{array}$ & Workers' options & $\begin{array}{c}\text { Presence of } \\
\text { further } \\
\text { mandatory } \\
\text { savings with } \\
\text { no degree of } \\
\text { choice } \\
\end{array}$ & Notes \\
\hline Argentina & $11 \%$ & $\begin{array}{l}\text { DB plan run by the public or DC } \\
\text { private pension funds. }\end{array}$ & Yes & $\begin{array}{l}\text { The possibility to choose } \\
\text { ended in } 2009 \text {. }\end{array}$ \\
\hline Australia & $9 \%$ & $\begin{array}{l}\text { Several pension plans run by } \\
\text { private pension funds. }\end{array}$ & No & \\
\hline Hungary & $33.5 \%$ & $\begin{array}{l}\text { Choice between old DB* system } \\
\text { and new mixed DB/DC system. }\end{array}$ & No & $\begin{array}{l}\text { The choice had to be done in } \\
1998 \text { and it applied only to } \\
\text { individuals that were already } \\
\text { working at the time }\end{array}$ \\
\hline Mexico & $\begin{array}{l}11.5 \% \text { plus extra } \\
\text { savings depending on } \\
\text { wage bracket. }\end{array}$ & $\begin{array}{l}\text { Several pension plans run by } \\
\text { private pension funds. }\end{array}$ & No & \\
\hline Netherlands & Usually around $16 \%$ & $\begin{array}{l}\text { Several pension plans run by } \\
\text { occupational pension funds. }\end{array}$ & Yes & $\begin{array}{l}\text { Contribution to occupational } \\
\text { plans is quasi-mandatory } \\
\text { being compulsory for } 90 \% \\
\text { of workers. }\end{array}$ \\
\hline New Zealand & $4 \%$ or $8 \%$ & $\begin{array}{l}\text { Several pension plans run by } \\
\text { private pension funds. }\end{array}$ & No & $\begin{array}{l}\text { Can choose to opt out from } \\
\text { mandatory contribution }\end{array}$ \\
\hline Norway & $\begin{array}{l}\text { Depends on employer, } \\
\text { but minimum is } 2 \%\end{array}$ & $\begin{array}{l}\text { Several pension plans run by } \\
\text { occupational pension funds. }\end{array}$ & Yes & \\
\hline Peru & $13 \%$ & $\begin{array}{l}\text { Choice between a public pension } \\
\text { and private pension funds. }\end{array}$ & No & \\
\hline Poland & $19.52 \%$ & $\begin{array}{l}\text { Choice between old DB system } \\
\text { and new NDC system. }\end{array}$ & No & $\begin{array}{l}\text { The choice had to be done in } \\
1999 \text { and it only applied to } \\
\text { individuals born between } \\
1949 \text { and } 1968\end{array}$ \\
\hline Sweden & $2.5 \%$ & $\begin{array}{l}\text { Several pension plans run by } \\
\text { private and public pension funds. }\end{array}$ & Yes & \\
\hline $\mathrm{UK}^{* *}$ & Usually around $6 \%$ & $\begin{array}{l}\text { DB plan run by the state or } \\
\text { occupational pension funds. }\end{array}$ & Yes & \\
\hline United States & $\begin{array}{l}\text { No fixed amount (but } \\
\text { has absolute upper } \\
\text { thresholds) }\end{array}$ & $\begin{array}{l}\text { Employers offer several pension } \\
\text { plans run by private pension } \\
\text { funds. }\end{array}$ & Yes & \\
\hline Uruguay & $7.5 \%$ & $\begin{array}{l}\text { Several pension plans run by } \\
\text { private and public pension funds. }\end{array}$ & Yes & \\
\hline
\end{tabular}

*DB: definite benefit; DC: definite contribution. ** The British pension system is currently undergoing some changes following the introduction of the 2011 Pension Bill. According to this reform, employees will still retain the right to choose where to invest a certain share of their income and in addition, a further share will be automatically invested in an occupational fund unless the employee opts-out. Since the details of this latter mechanism have not been fully established at the time of the writing, we decided to report in the table only the mandatory components that were already present.

Sources: The information provided in the table was obtained from SSA (2010a), SSA (2010b) and OECD (2011).

In this new scenario, the issue of obtaining an adequate degree of information and financial literacy has been raised by several researchers, in that the choice of both the amount and the composition of the retirement-saving-portfolio implies the understanding and the evaluation of the different opportunities that are now offered. However, although several papers have produced a solid piece of evidence on the relevance of financial literacy in determining the "planning attitude" or the degree of farsightedness of individuals ${ }^{1}$, to

\footnotetext{
${ }^{1}$ The literature on financial literacy has stressed the importance of this factor in the financial decisions of individuals and in particular in saving behaviour and retirement decisions (for an overview of this issue see OECD 2005). Most works on this subject approach the issue from a behavioural perspective or through empirical analyses: Clark et al. (2003) compare questionnaires about retirement goals filled by the same individuals before and after attending a financial seminar and note how retirement decisions change after such an event. Lusardi and Mitchel (2009) perform an analysis with an American dataset containing detailed information of both the
} 
the best of our a knowledge scarce effort has been put on the theoretical analysis of the effects that the cost of achieving such an adequate level of information and financial knowledge can play in determining workers' optimal decisions. A notable exception is the model worked out by Jappelli and Padula (2011) where the degree of financial literacy determines the returns of saving: given that financial literacy is costly, the authors use their model to determine the optimal investment in literacy and to assess how this mechanism affects saving behaviour. Their paper however does not analyse the role of literacy on the choice between different investment plans and, moreover, they build a model where returns are non-stochastic: these are two aspects that will be crucial in our contribution. Also Lusardi et al (2011) explore the issue of optimal financial literacy and they develop a numerically-simulated life cycle model where endogenous financial literacy affects the stochastic returns from saving and where exogenous education determines income.

Given these premises, in this paper we aim at exploring how the existence of a cost to achieve the necessary degree of information to understand and access an investment plan can affect the distribution of investment decisions in the population and how it interacts with the wage level, preferences of different individuals and financial literacy investment decisions.

More precisely, the scope of the present paper is twofold: on one hand, to build a model describing the determinants of individuals' decisions on the amount and the allocation of retirement saving in presence of a) mandatory contribution; b) the opportunity of investing the mandatory contribution in plans involving different interest rates and volatility; c) information costs to access the more complex plans and d) a relationship between these costs and financial literacy. On the other hand, to provide a normative analysis of the optimal contribution rate that public authority should set.

\subsection{Previous related literature}

Our paper has much to do with previous literature on overlapping generation models dealing with consumption and retirement saving in the presence of public pensions (for example, Samuelson 1958 and 1975 or Blake 2006 for a broader overview), although the presence of uncertain returns from pension plans makes our case different from the basic ones. Some articles have analysed pension systems where saving decisions are taken under some degree of uncertainty: Demange (2009), for example, builds an overlapping generation model with macro shocks and assesses the political support by new generations to different rates of contribution and intergenerational risk sharing; D'Amato and Galasso (2010) use an overlapping generation model with shocks on aggregate production to compare the optimal and the politically feasible level of intergenerational risk sharing. Somehow differently, Maurer et al. (2010) perform an empirical analysis of the effect of uncertainty in labour income on the life-cycle portfolios. Similarly to Gordon and Varian (1988), we model directly the uncertainty from the returns on retirement savings. However we depart from this work in that we do not focus on intergenerational risk sharing ${ }^{2}$ and we allow for voluntary savings to be optimally chosen and for the existence of different investment opportunities.

More recently, a number of studies have analysed the consequences of stochastic returns from retirement savings and their consequences on the optimal portfolio composition. Wagener (2003) builds a model where voluntary savings are chosen optimally and they coexist with compulsory retirement savings: both forms of savings yield stochastic returns and the model is used to compare fixed contribution to fixed retribution pension systems. An even more portfolio oriented ${ }^{3}$ approach is contained in Dutta et al. (2000) where they derive, under a mean-variance utility function, the optimal allocation of exogenously determined retirement savings between funded and unfunded pension plans/schemes: the two plans display different stochastic returns and the optimal allocation is obtained under the assumption that no other form of saving is present. Also Matsen and Thogersen (2004) adopt a portfolio approach and build a model where a given amount of saving has to be allocated between risky and safe assets given that a share of individuals' saving is forcedly invested in funded and unfunded PAYG pension plans: the authors derive thus the optimal allocation of

\footnotetext{
retirement planning decisions and financial knowledge of individuals and find a strong influence of the latter. Still on the American case, but with a different database, Lusardi and Mitchel (2011) analyse how the lack of financial literacy is particularly relevant in the decision of some categories of individuals while Fornero and Monticone (2011) explore this issue for Italy finding evidence that financial literacy is usually scarce and that participation to pension plans in general and to riskier options in particular, is significantly influenced by it.

${ }^{2}$ Related to the Gordon and Varian (1988) work on intergenerational risk sharing is Veall (1986).

${ }^{3}$ Clearly, some classic works like Phelps (1962), Merton (1969) and Samuelson (1969) have analysed optimal portfolio decision under uncertain returns, however, they did not focus on retirement savings nor on fixed contribution rates nor on the possibility of choosing between alternative schemes.
} 
voluntary savings as well as the optimal dimension and composition of the PAYG system. De Menil et al. (2006) develop a normative analysis to determine the optimal balance between current consumption, voluntary funded saving and compulsory retirement saving, where returns from both forms of savings are stochastic but only a single pension plan exists. Finally, Corsini et al. (2012) argue that choices on pension plans can affect workers' career, such that, in turn, the latter effect can play a role in their very decisions.

Our work focuses on the agents' choice of a single pension plan among different alternatives and it explores this choice process both from a positive and normative perspective. Our model determines the optimal portfolio composition of retirement-savings, so that it shares some features with Dutta et al. (2000) and Matsen and Thorgsen (2004) but we crucially depart from these works by allowing for consumption to be optimally determined, for the presence of information costs, financial literacy and wage heterogeneity. On the other hand, for the sake of tractability, we assume that returns from voluntary savings are not stochastic, though we discuss how to relax this assumption in the normative part of our analysis.

Empirical analyses have also explored the determinants of investments in assets with uncertain returns. While not directly tackling the issue of planning for retirement, the analyses by Bertaut and Haliassos (1995), Christiansen et al. (2007) and van Rooij et al. (2011) highlight how risky assets are usually chosen by individuals with higher income and higher financial literacy. In particular Bertaut and Haliassos (1995) suggest how their evidence can be explained, among others, by the presence of some information costs that are associated to riskier and more complex assets. The role of complexity also emerges in Iyengar et al. (2004) where the authors, using data concerning the 401k plan participation in the US, show that providing individuals with too many choice options on the specific characteristics of the plan may lead to lower motivation towards the optimal choice so that complexity does affect the final choice. Moreover, the authors argue that workers' wide opportunity set can create a burden for workers that is related to the time lost in keeping track of the different options.

Following these contributions, in our model we allow for the presence of a cost that has to be paid in order to obtain the information to fully understand and assess an investment plan. We call this an "information cost" and it must be paid to access a given plan. This cost can have a component that is related to the time lost to fully understand the plan (i.e. it is an opportunity cost, as also suggested by Bertaut and Haliassos 1995 and Iyengar et al. 2004) and is related to the complexity of the plan (so that it can be assumed to be zero for simpler/safer investment plans) and, possibly, on the degree of financial literacy of individuals.

Some of the results we provide are expected: expected rate of returns and volatility have an important role in the attractiveness of the plans, and similarly, higher risk aversion (propensity) of the individuals pushes the favour toward a safer (riskier) option.

Some results are less obvious: first, we show that the role of wages in affecting the portfolio decision can be, in principle, non-monotonic and it depends on the shape of information costs, on the level of contribution rate and on the individuals' attitude towards risk. Second, we show that the role of income is clear-cut and in line with the above cited empirical findings under non-increasing relative risk aversion: if this is the case, then the cost necessary to achieve an adequate degree of financial knowledge typically discourages low income workers from opting for more complex plans. Third, we characterize the optimal contribution rate to complementary pension plans and we show that it crucially depends on the degree of attractiveness of the pension plan and on the degree of risk aversion: more precisely, it is an increasing (decreasing) function of wage if relative risk aversion is decreasing (increasing). Finally, following Jappelli and Padula (2011) and Lusardi et al (2011) we also provide a framework in which financial literacy is endogenously chosen by individuals: in particular, we imagine that individuals can invest in financial literacy and, differently from the latter contributions we assume that this investment allows to reduce the information cost to access the complex plan. By introducing this new assumption we are also able to obtain an optimal level of financial literacy and we show that, among others, it is an increasing function of wage.

The rest of the paper is organized as follows: after reviewing the literature related to our work, in section 2 we build a model of optimal consumption and saving in the presence of a mandatory pension plan with stochastic returns and, in section 3, we allow for alternative investment opportunities, some of which entail information costs, and examine the determinants of workers' decision, by focusing on the role of wages in section 4; moreover, in section 5 we discuss the role of the mandatory contribution rate and then we carry out a normative analysis which allows us to determine the optimal level of such a contribution rate. In section 6 we extend our model in order to deal with more sophisticated preferences and with endogenously determined financial literacy. As for the former, we introduce decreasing risk aversion and, as for the latter, we allow for variable amount of financial literacy investment that directly reduces information costs. Finally, in section 7 we conclude. 


\section{Consumption and saving in the presence of mandatory complementary pension plans}

We imagine a small closed economy where individuals live two periods: in the first period they work and consume part of their income, given by wage $w$, whereas in the second they consume what they have saved. In particular, savings are partly voluntary and partly compulsory: for the sake of simplicity we assume that voluntary saving is accumulated at the safe rate $r^{4}$. As for the compulsory component, for the sake of simplicity, we omit the existence of a mandatory PAYG pension scheme ${ }^{5}$ and we assume that workers have to adhere to a complementary pension plan $i$ (which is usually referred to as the second pillar) where they must invest a fixed share of their income. The exact rate of compulsory contribution $\gamma$ is fixed by law and the plan $i$ yields stochastic returns $r_{i}$ that are drawn from a normal distribution, so that $r_{i} \sim N\left(\bar{r}_{i}, \sigma_{i}{ }^{2}\right)$, where $\bar{r}_{i}$ and $\sigma_{i}^{2}$ are, respectively, mean and variance of the returns. Some plans may display a zero variance so that they yield fixed returns and are equivalent to investing in a safe asset. In addition, workers have to pay a cost $C_{i}$ (which in some cases can be zero) to access the $i$ plan. This is an information cost and it depends on the complexity of the mechanism governing the plan and to the effort needed to keep track of the performance of the asset. This cost can be seen as the cost necessary to obtain enough information to fully understand and assess the plan and from this point of view it could be related to the financial literacy of workers: this relationship with literacy will be better covered in section 6 . To all extents, these information costs reduce the desirability of the plan.

Given the above discussion we can write down the following budget constraint:

$$
c_{2}=\left[(1-\gamma) w-c_{1}-C_{i}\right](1+r)+\gamma\left(1+r_{i}\right)
$$

where $c_{1}$ and $c_{2}$ represent consumption in the first and second period respectively. Given that $r_{i}$ is a random variable, $c_{2}$ is stochastic and is actually normally distributed ${ }^{6}$.

Workers lifetime utility $U$ is a function on the consumption in the two periods so that $U=U\left(c_{1}, c_{2}\right)$, where monotonicity and concavity on consumption are assumed. Workers choose how much to consume (and thus to save) in the first period aiming to obtain the highest expected utility (denoted as $E\left[U\left(c_{1}, c_{2}\right)\right]$ ); the problem they face is then

$$
\left\{\begin{array}{l}
\max _{c_{1}} E\left[U\left(c_{1}, c_{2}\right)\right] \\
\text { s.t. } c_{2} \sim N\left[\left(w-c_{1}-C_{i}\right)(1+r)+\gamma w\left(\bar{r}_{i}-r\right), \gamma^{2} w^{2} \sigma_{i}^{2}\right] . \\
\text { s.t. } c_{1}, E\left(c_{2}\right) \geq 0
\end{array}\right.
$$

The first constraint represents the budget constraint from eq. (1) while the second constraint implies that individuals cannot choose a negative consumption in the first period and that they cannot borrow an amount greater than what they can, on average, give back in the second period ${ }^{7}$.

From an analytical point of view, the above problem is not trivial as it requires the computation of the expected utility of a gamble (concerning the realization of consumption in the second period, in our case). To obtain a closed form solution we assume that lifetime utility takes the following form:

$$
U=-e^{-a c_{1}}-\rho e^{-a c_{2}}
$$

\footnotetext{
${ }^{4}$ In any case, we discuss in section 5 how this simplifying assumption is not crucial for the normative analysis.

${ }^{5}$ In fact, typically individuals have no degree of choice on the investment of such component (usually called first pillar) and its inclusion in the model would not alter our results.

${ }^{6}$ Since we are assuming normality of returns we cannot exclude the possibility of a negative realization of consumption in the second period. However, this is an extreme possibility that happens with probability almost (but not) zero. In this extreme case we may interpret the negativity of consumption imagining that the individuals have to cover the losses with some extra work in the second period, which, for simplicity, we assimilate to a negative consumption.

${ }^{7}$ Since individuals prefer to smooth consumption and have no labour income in the second period, borrowing will take place only for extremely high rates of compulsory contribution.
} 
where $\rho \in(0,1]$ is the intertemporal discount factor and $a>0$ is the coefficient of absolute risk aversion and constant absolute risk aversion (CARA) is thus implied. In section 6 we will extend the model to allow for variable risk aversion.

We can solve the above using a property ${ }^{8}$ of exponential utility functions: in fact, for any given stochastic variable $z_{j}$ distributed normally with mean $z$ and variance $\sigma_{z}^{2}$ we have that $E\left(e^{-a z_{j}}\right)=e^{-a\left(z-a \sigma_{z}^{2} / 2\right)}$. Since in our case consumption in the second period is normally distributed we can exploit this property and obtain

$$
\left\{\begin{array}{l}
\max _{c_{1}}-e^{-a c_{1}}-\rho e^{-a\left(\bar{c}_{2}-a \sigma_{c_{2}}^{2} / 2\right)} \\
\text { s.t. } c_{2} \sim N\left[\left(w-c_{1}-C_{i}\right)(1+r)+\gamma w\left(\bar{r}_{i}-r\right), \gamma^{2} w^{2} \sigma_{i}^{2}\right] \\
\text { s.t. } c_{1}, E\left(c_{2}\right) \geq 0
\end{array}\right.
$$

where $\bar{c}_{2}$ and $\sigma_{c_{2}}^{2}$ are, respectively, mean and variance of consumption in the second period. From the solution of the above we obtain ${ }^{9}$ the following optimal consumption $\left(c_{1, i}^{*}\right.$ and $\left.c_{2, i}^{*}\right)$ :

$$
c_{1, i}^{*}=\left[\left(1+d_{i}\right) w x-\frac{\log \rho x}{a}\right] \frac{1}{(1+x)}
$$

$$
c_{2, i}^{*} \sim N\left\{\left[\left(1+d_{i}\right) w x+\frac{\log \rho x}{a}\right] \frac{x}{(1+x)}, \gamma^{2} w^{2} \sigma_{i}^{2}\right\}
$$

$$
E\left(U_{i}^{*}\right)=-(1+x) x e^{-a\left(1+d_{i}\right) w_{1+x}} \rho^{\frac{1}{1+x}}
$$

where $x=1+r, d_{i}=\gamma \frac{\bar{r}_{i}-r-\gamma a w \sigma_{i}^{2} / 2}{x}-\frac{C_{i}}{w}$. Eq. (5c) describes the indirect expected utility of a worker under the plan $i$. The above equations refer to the inner solution of the maximisation problem and they arise as long as the following condition holds:

$$
w \geq \max \left[\frac{\log \rho x}{\left(1+d_{i}\right) a x},-\frac{\log \rho x}{\left(1+d_{i}\right) a x}\right]
$$

Since the analysis of the corner solutions is beyond the scope of the present paper, (for a study of this issue see Corsini and Spataro 2012), in the rest of the paper, for the sake of simplicity, we assume that the above condition holds true, so that the interiority of solutions is always satisfied.

\section{Choosing between alternative plans}

We analyse now how workers behave when they are given the possibility to choose between different complementary pension plans (or schemes). In particular we imagine that workers can choose between two possible plans: a safe plan and a risky plan. The fact that individuals have to strictly choose between different plans without the possibility of mixing them appears to be the most realistic case as we have described in Table 1 . However, in section 5, we discuss how the possibility of mixing plans would affect our model.

If workers are given the possibility to choose between two schemes they will typically proceed in two steps: first they will choose which scheme to adhere to and then they will choose consumption and saving so

\footnotetext{
${ }^{8}$ This is a well-known result: see Varian (1993). Note also that our approach is equivalent to the use of a mean/variance utility function as is done, among others, by D'Amato and Galasso (2010).

${ }^{9}$ See Appendix A for the algebraic derivations.
} 
as to maximise their expected utility. As a solution strategy we solve the problem through backward induction: we start from the last step, where workers determine their indirect utility (through optimal consumption and voluntary saving) in a given plan $i$ (which is given by (5c)) and then we go back to the first step where workers choose the plan that yields the highest indirect utility, in which investing their compulsory savings.

\subsection{Safe plan}

We imagine that the safe plan $S$ yields a certain return $r_{S}$ with zero variance. For simplicity, and without loss of generality, we assume that the returns of this plan are the same as those on voluntary saving so that $r_{S} \sim N(r, 0)$. Moreover, given the simplicity of this plan, we assume that no information costs have to be paid to access and understand it so that $C_{S}=0$. Given the characteristics in terms of returns and costs of this plan it descends that $d_{S}=0$ and the solutions in eq. (5a)-(5c) take the following form:

$$
c_{1, S}^{*}=\left(w x-\log \frac{\rho x}{a}\right) \frac{1}{(1+x)}
$$

$$
c_{2, S}^{*}=\left(w x+\log \frac{\rho x}{a}\right) \frac{x}{(1+x)}
$$

$$
E\left(U_{S}^{*}\right)=-(1+x) e^{-a w \frac{x}{1+x}} \rho^{\frac{1}{1+x}}
$$

Note that consumption ${ }^{10}$ in both periods is a deterministic variable.

\subsection{Risky plan}

Under the risky plan workers obtain returns $r_{R}$ which are drawn from a distribution $r_{R} \sim N\left(\bar{r}_{R}, \sigma_{R}^{2}\right)$ where $\bar{r}_{R}$ and $\sigma_{R}^{2}$ are mean and variance respectively. Given the risky nature of this plan we assume that $\bar{r}_{R}>r$ : in fact if the latter inequality does not hold, such a plan would be clearly unattractive and all (risk averse) workers would simply choose the safe plan.

We also assume that in this plan $C_{R}>0$, implying that a certain amount of information costs has to be paid to access it. This is partly a direct fixed cost (for example the price of informative material or the fee to attend a course on finance) and partly an opportunity cost (related to the time lost to understand and to keep track of the plan). In particular, we assume $C_{R}=F+f \cdot w$ where $F \geq 0$ is the fixed component and $f \cdot w \geq 0$ is the opportunity cost component which is then related to worker's wage/income. ${ }^{11}$

In the analysis we cover only the case $f \geq 0$ because, within our framework, the variable component is due, if present, to opportunity costs. However, it is possible that higher income is also correlated to better financial knowledge and literacy and therefore, information costs could be less relevant for richer workers. In this section we assume that, for a given income, these costs are the same for all individuals and thus $i$ ) either they are not affected by financial literacy or $i$ ) financial literacy is the same for all individuals irrespectively of wage. In section 6 instead, we model directly the relationship between information costs and (endogenous) financial literacy, allowing individuals to acquire financial literacy to reduce the information costs.

This said, eqs. (5a)-(5c) for the risky plan become:

\footnotetext{
${ }^{10}$ In this case the optimal levels of consumption and the indirect utility do not depend on the contribution rate because individuals can borrow at the risk free rate.

${ }^{11}$ Note that while the magnitude of these costs may depend on income, it does not depend on the actual amount saved nor by the contribution rate; that is, once the cost has been paid, the amount invested in the pension fund does not affect it.
} 


$$
c_{1, R}^{*}=\left[w\left(1+d_{R}\right) x-\log \frac{\rho x}{a}\right] \frac{1}{(1+x)}
$$

$$
c_{2, R}^{*} \sim N\left\{\left[\left(1+d_{R}\right) w x+\log \frac{\rho x}{a}\right] \frac{x}{(1+x)}, \gamma^{2} w^{2} \sigma_{R}^{2}\right\}
$$

$$
E\left(U_{R}^{*}\right)=-(1+x) e^{-a\left(1+d_{R}\right) w_{\frac{x}{1+x}}} \rho^{\frac{1}{1+x}}
$$

where

$$
d_{R}=\gamma \frac{\bar{r}-r_{s}-\gamma a w \sigma_{R}^{2} / 2}{x}-f-\frac{F}{w}
$$

\subsection{Incentive function for the adhesion to the risky plan}

We now have all the ingredients to compare the expected indirect utilities stemming from the two plans. If we define the incentive to adhere to the risky plan as $I=E\left(U_{R}^{*}\right)-E\left(U_{S}^{*}\right)$ then the value of $I$ determines the choice of the individuals: in fact a worker will opt for the risky plan whenever $I>0$ and for the safe plan for $I \leq 0^{12}$. We can easily compute the value of $I$ from eqs. (7c) and (8c):

$$
I=E\left(U_{R}\right)-U_{S}=(1+x)\left(1-e^{-a d_{R} w \frac{x}{1+x}}\right)(x e)^{-\frac{x}{1+x} a w} \rho^{\frac{1}{1+x}} .
$$

The above result allows us to provide the following proposition:

\section{PROPOSITION 1}

$A$ worker chooses the risky plan if and only if $d_{R}>0$.

\section{PROOF}

The maximization of expected utility implies that a worker chooses to adhere to the risky plan if and only if $I>0$ and thus, from eq. (10), a worker adheres to it if and only if $(1+x)\left(1-e^{-a d_{R} w}\right)^{-\frac{x}{1+x}}(x e)^{-\frac{x}{1+x} a w} \rho^{\frac{1}{1+x}}>0$. Since the parameters $a, w, x$ and $\rho$ are necessarily positive this inequality holds true for $\left(1-e^{-a d_{R} w}\right)>0$ which is true if and only if $d_{R}>0$.

Proposition 1 states that the choice of workers depends only on $d_{R}$ and therefore we can study the determinants of the choice simply analysing the variable $d_{R}$. Clearly it follows that for $d_{R} \leq 0$ individuals opt for the safe plan. More in particular, the following condition determines the choices of workers:

$$
I>0 \Leftrightarrow d_{R}>0 \Leftrightarrow-\frac{a \gamma^{2} \sigma^{2}}{2 x} w^{2}+\gamma\left(\frac{\bar{r}-r_{s}-f \cdot x / \gamma}{x}\right) \cdot w-F>0 .
$$

Moreover we can assert the following remark which qualifies the shape of the incentive function:

\section{REMARK 1 TO PROPOSITION 1}

For any $\gamma>0, d_{R}$ is an increasing function of $\bar{r}-r_{s}$ and a decreasing function of $a, \sigma^{2}, f$ and $F$.

\section{PROOF}

By computing the derivatives of $d_{R}$ (as defined by eq. (9)) with respect to the relevant parameters we have:

$$
\partial d_{R} / \partial\left(\bar{r}-r_{s}\right)=\gamma / x>0 ; \partial d_{R} / \partial a=-\gamma^{2} \cdot \sigma^{2} \cdot w / 2 x<0 ; \partial d_{R} / \partial \sigma^{2}=-\gamma^{2} \cdot a \cdot w / 2 x<0 ; \partial d_{R} / \partial f=-1<0 \text { and }
$$
$\partial d_{R} / \partial F=-1 / w<0$.

\footnotetext{
${ }^{12}$ By convention, we assume that for $I=0$ the individuals choose the safe scheme.
} 
The results contained in the above remark are quite intuitive: they state that workers are more likely to opt for the risky scheme when the difference between the mean returns of the risky and of the safe scheme is higher, and less likely the more adverse to risk the individuals, the more volatile the returns of the risky scheme and the larger the costs to access the risky scheme. Note that the results in Remark 1 can be extended to the incentive function as a whole so that the value of $I$ is increasing in $\bar{r}-r_{s}$ and decreasing in $a, \sigma^{2}, f$, and $F$.

Things are more complex as for the role that the wage $w$ and the rate of compulsory contribution $\gamma$ have on the choice of workers: these aspects appear to be crucial in the choice process and a detailed analysis of their role will be at the centre of the next two sections.

\section{The role of wages}

A relevant element affecting the value of $d_{R}$ is the wage $w$, so that workers of different wage levels may prefer different plans: this in turn may imply a partition of the population where only some categories of workers opt for the risky plan while others opt for the safe asset only. In particular $w$ does not affect monotonically $d_{R}$ and in fact, as we can see from eq. (11), the sign of $d_{R}$ is determined by a second order equation in $w$. This allows us to state the following proposition:

\section{PROPOSITION 2}

There exist two values of wages, $w_{1}$ and $w_{2}$, for which $d_{R}=0$. Then, for any $\gamma>0$, for wage levels within the interval $\left(w_{1}, w_{2}\right)$ workers choose the risky plan and for wage levels outside the interval workers choose the safe plan.

\section{PROOF}

We know from Proposition 1 that workers choose the risky plan if and only if $d_{R}>0$. From eq. (11) we see that the sign of $d_{R}$ is determined by a second order equation in $w$ with negative second order coefficient: therefore there are two values of $w$ for which $d_{R}=0$ and $d_{R}$ is positive for values of $w$ that are outside the interval whose boundaries are the roots of eq. (11).

In particular $w_{1}$ and $w_{2}$ take the following values:

$$
\left\{\begin{array}{l}
W_{1}=\frac{\bar{r}-r_{s}-f \cdot x / \gamma-\sqrt{\left(\bar{r}-r_{s}-f \cdot x / \gamma\right)^{2}-2 a \sigma^{2} F x}}{a \gamma \sigma^{2}} \\
W_{2}=\frac{\bar{r}-r_{s}-f \cdot x / \gamma+\sqrt{\left(\bar{r}-r_{s}-f \cdot x / \gamma\right)^{2}-2 a \sigma^{2} F x}}{a \gamma \sigma^{2}} .
\end{array}\right.
$$

The above equations ${ }^{13}$ imply that whenever $\bar{r}-r_{s}>\sqrt{2 a \sigma^{2} F x}$ there exists a minimum rate of contribution $\left(\gamma^{M I N}\right)$ which is necessary and sufficient for $w_{1}$ and $w_{2}$ to exist and be positive:

$$
\gamma^{M I N}=\frac{f \cdot x}{\bar{r}-r_{s}-\sqrt{2 a \sigma^{2} F x}} .
$$

On the contrary, when $\bar{r}-r_{s} \leq \sqrt{2 a \sigma^{2} F x}$, the incentive is negative for any level of wages and of the contribution rate.

\footnotetext{
${ }^{13}$ The values $w_{l}$ and $w_{2}$ exist and are positive for: $\left(\bar{r}-r_{s}-f \cdot x / \gamma\right)^{2}>2 a \sigma^{2} F x$ and $\bar{r}-r_{s}-f \cdot x / \gamma>0$. When the former condition is not met the incentive cannot be positive for any level of wages, when the latter is not met, the incentive cannot be positive for any positive level of wages. These conditions have an economic interpretation: they tell us that in order for the risky scheme to be attractive, the difference between the mean returns of the two schemes has to make up for the costs due to the uncertainty of the risky scheme (which are related to $a, \gamma$ and $\sigma^{2}$ ) and to the entry costs requirements (which are related to $F, f$ and $x$ ).
} 
A graph can be helpful to understand the role of wages in the choice of workers: in Figure 1 we draw a curve depicting $d_{R}$ as a function of $w$ for a given contribution rate: when the curve is above zero, $d_{R}$ is positive and so is the incentive: workers choose the risky plan; symmetrically, when the curve is below zero workers opt for the safe plan.

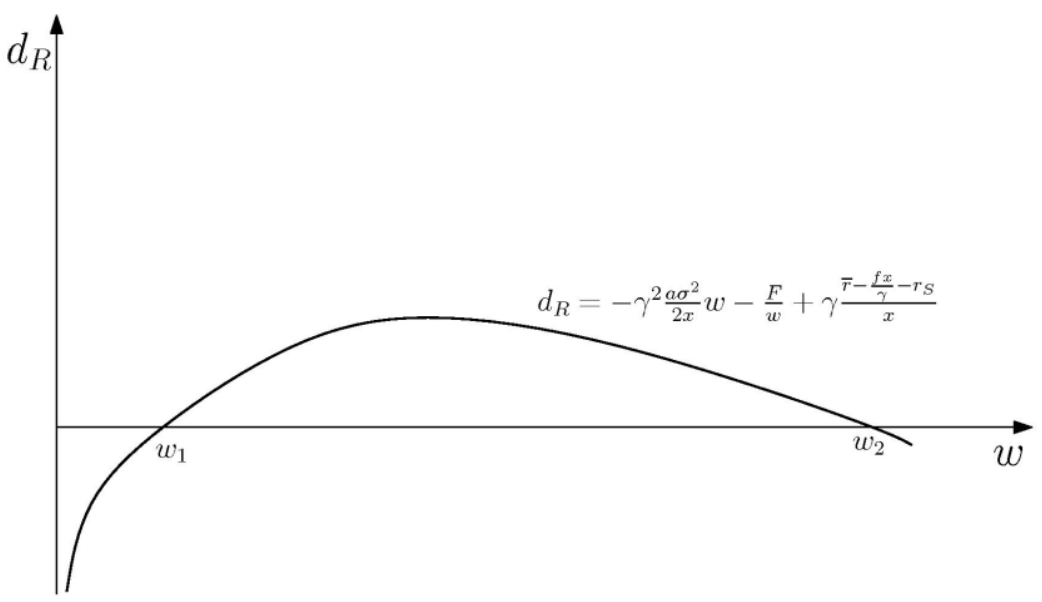

Figure 1: The incentive to adhere to the risky plan in relation to wages

A relevant economic feature of our results is the following: there exists a minimum wage threshold $\left(w_{l}\right)$ below which workers do not choose to invest in the risky plan: the reason for this rests on the fact that when wages are low, the size of the investment $(\not w)$ in the risky plan is too low to compensate the costs to obtain the required degree of information. As for the second wage threshold $\left(w_{2}\right)$ our analysis shows that above such level workers do not invest in the risky scheme either: in this case the reason relies on the fact that if the size of the investment is too high, the variance of expected consumption grows exponentially, producing a lower expected utility for risk averse individuals.

Note that, from a social policy point of view, the exclusion of the low income class from the risky scheme might be problematic as it does not descend strictly from their preferences (as in the case of the high income class) but rather by the relatively too high cost necessary to obtain the required degree of information and financial knowledge to access the risky scheme, so that their freedom of choice is somehow constrained by their scarcity of resources. Moreover, since the result concerning high-level individuals is somehow ad odds with empirical evidence, we will discuss its robustness in section 6 , where we remove the hypothesis of constant absolute risk aversion.

In the next section we analyse the role of the contribution rate.

\section{The rate of compulsory contribution and its optimal level}

Previous section considered the value of the rate of contribution $\gamma$ as fixed at a certain level: here first we analyse how $\gamma$ affects the incentive function and then we examine what happens when $\gamma$ can be chosen optimally by a benevolent policy maker or by the very individuals.

Preliminarily we should note from eq. (7) that the effect of $\gamma$ on $d_{R}$ is not monotonic. This said, some interesting results are obtained if we consider the effect of $\gamma$ conjunctly with $w$. In particular, starting from Proposition 2 we can see that eq. (12) defines two curves (described from the equations for $w_{1}$ and $w_{2}$ ) which determine the couples $(w, \gamma)$ for which $d_{R}$ (and thus $I$ ) is equal to zero: those curves determine also the regions in the $(w, \gamma)$ space for which workers adhere to the risky plan and their shapes differ depending on whether $f>0$ or $f=0$. We depict the curves ${ }^{14}$ for the two cases in Figures $2 \mathrm{a}$ and $2 \mathrm{~b}$.

\footnotetext{
${ }^{14}$ Note that the two curves go to zero for $\gamma \rightarrow \infty$. In addition, for $f>0$, the two curves cross at $\gamma=\gamma^{M I N}$ and $w_{l}$ is monotonically decreasing while $w_{2}$ has a maximum. The formal analysis of the shapes of these curves is available upon request to the authors.
} 

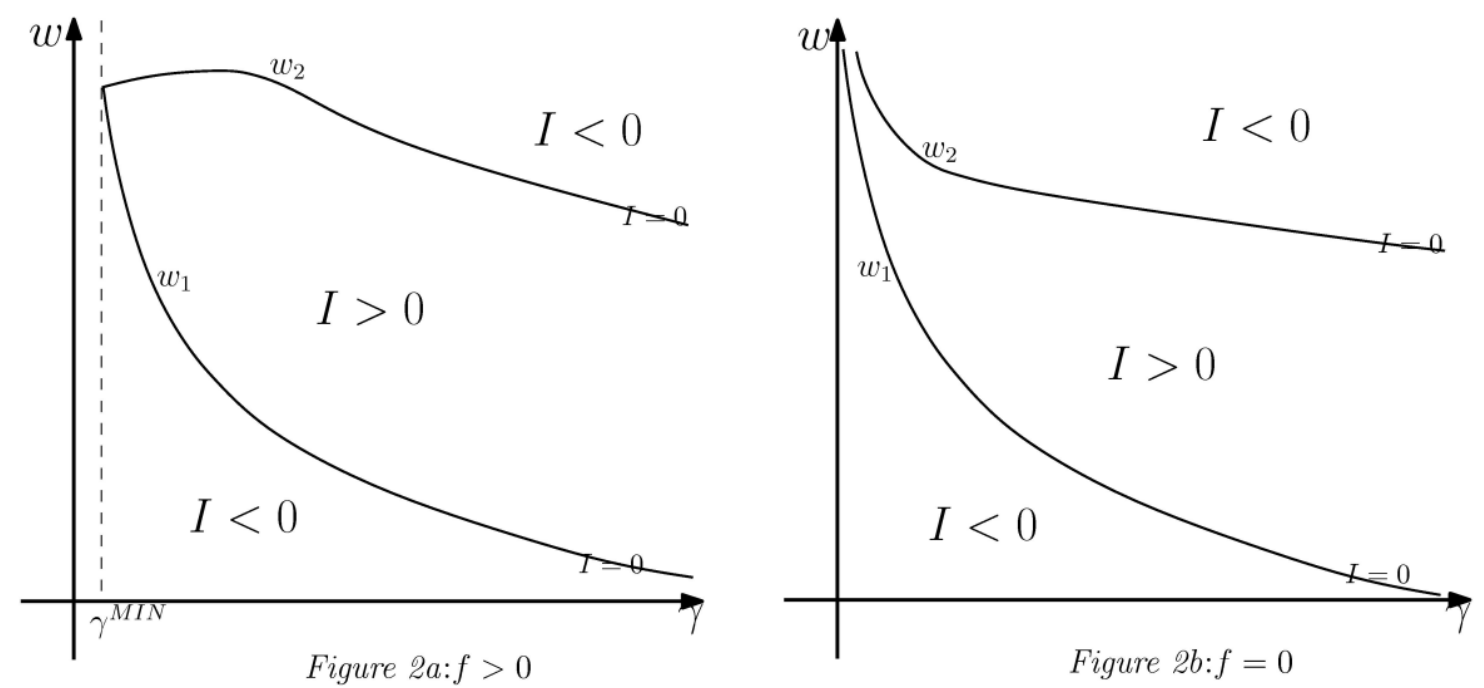

Figure 2: Sign of the incentive as a function of the contribution rate and wage

For both cases, the area between the two curves pinpoints the values of $\gamma$ and $w$ for which workers choose the risky plan while, on the contrary, outside those curves workers invest in the safe plan. Basically, in order to induce the adhesion to the risky plan the value of $\gamma$ should neither be too small nor too large. There is a clear economic interpretation to this result: on the one hand the compulsory rate of contribution cannot be too small, otherwise the resulting investment would be too small to cover the entry costs; on the other hand, a too large $\gamma$ would generate too high volatility in the returns, making the risky plan unattractive. Note that from eq. (13) we know that for $f>0$ there exists a lower bound for the rate of contribution ( $\gamma^{M I N}$ in Figure 2a) below which no worker opts for the risky plan: this is the main difference with the case of $f=0$.

The above considerations suggest the existence of a level of compulsory contribution that, on the one hand, maximising the value of $I$, is optimal to promote the adhesion to the risky scheme and, on the other hand, directly maximises the expected utility of all individuals. This latter property is relevant in two cases: first, from a normative perspective, whenever the government has to set a contribution rate that should be socially optimal; second, whenever the individuals are given the possibility to actually choose how much to invest in the pension plan. In the next proposition we derive formally the existence and the level of such optimal $\gamma$ :

\section{PROPOSITION 3}

There exists a value $\gamma^{*}$ that maximises the expected utility of individuals. Such value maximises the value of $d_{R}$ and of I and is given by $\gamma^{*}=\frac{\bar{r}-r_{s}}{a w \sigma^{2}}$.

\section{PROOF}

From eqs. (7c) and (8c) we know that $E\left(U_{S}^{*}\right)$ is unaffected by $\gamma$ and that $E\left(U_{R}^{*}\right)$ is an increasing function of $d_{R}$ and is only affected by $\gamma$ through $d_{R}$. Therefore, $E\left(U_{R}^{*}\right)$ reaches its maximum with respect to $\gamma$ whenever $\gamma=\gamma^{*}=\arg \max d_{R}$. Since $\partial d_{R} / \partial \gamma=\frac{\bar{r}-r_{s}-a w \gamma \sigma^{2}}{x}$ it descends that $\gamma^{*}=\frac{\bar{r}-r_{s}}{a w \sigma^{2}}$. Since this value maximises $E\left(U_{R}^{*}\right)$ and leaves unaffected $E\left(U_{S}^{*}\right)$, it maximizes the utility of all individuals.

\section{Several comments to Proposition 3 are worth doing.}

First of all, it has relevant policy implications: in fact it allows us to determine the exact rate that a policy maker should set in the attempt to maximise the utility of workers. The optimal rate is decreasing in wages and total contribution takes the form of a flat contribution equal to $\frac{\bar{r}-r_{s}}{a \sigma^{2}}$. 
Second, even if setting $\gamma=\gamma *$ is optimal it does not necessarily induce individuals to adhere to the riskier plan: in fact, there are values of the parameters for which $d_{R}\left(\gamma^{*}\right)<0$. In other words, while $\gamma^{*}$ always succeeds in maximising $d_{R}$ and the expected utility, it does not guarantee the incentive $I$ to be positive. In particular, it is easy to see from eq. (9) that $d_{R}\left(\gamma^{*}\right)>0$ if and only if

$$
\left[\frac{1}{2} \frac{\left(\bar{r}-r_{s}\right)^{2}}{a \sigma^{2} x}-F\right] \frac{1}{w}>f
$$

This an important point because it stresses the fact that information costs directly affect the investment decisions: in fact, when the costs are zero, condition (14) is always satisfied and the optimal contribution rate would induce individuals to choose the risky plan. Finally, from the above condition we see that, for $f>0$, workers above a certain wage will necessarily choose the safe plan. Hence, we can conclude that even when the contribution rate is set at its optimal rate, workers whose wage is above a certain threshold choose the safe plan. The value $w^{M A X}$ of that threshold is $\left[\frac{1}{2} \frac{\left(\bar{r}-r_{s}\right)^{2}}{a \sigma^{2} x}-F\right] \frac{1}{f}$; for the case $f=0$ the value of this threshold goes to infinity so that it is not binding.

Third, we should bear in mind that, for its very nature, the rate of compulsory contribution cannot be higher than 1 and therefore there could be situations for which a policy maker could not actually set $\gamma=\gamma^{*}$ : in those cases the contribution rate equal to 1 would be the second best solution.

We can summarize our findings by depicting in a graph the optimal rate of compulsory contribution: in Figure 3 below we represent the curve $\gamma^{*}$ along with the curves ${ }^{15} w_{1}$ and $w_{2}$ and the constraint $\gamma<1$.

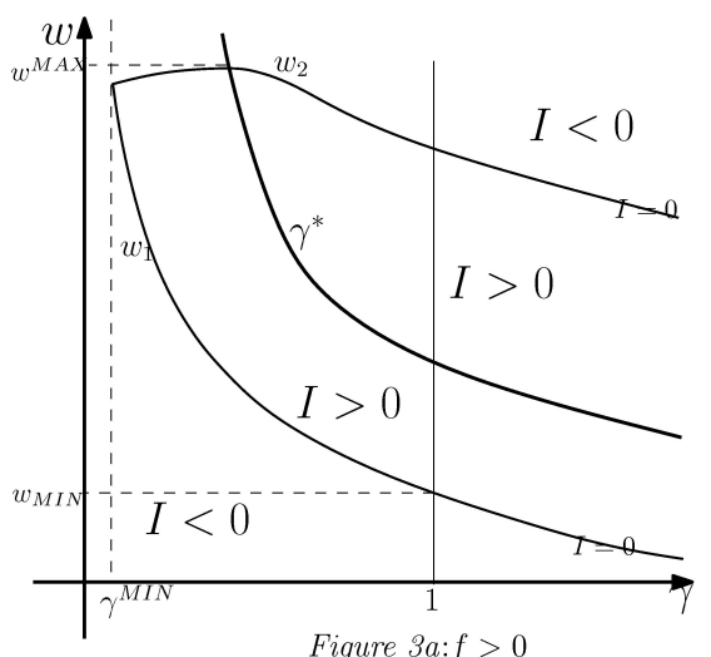

Figure $3 a: f>0$

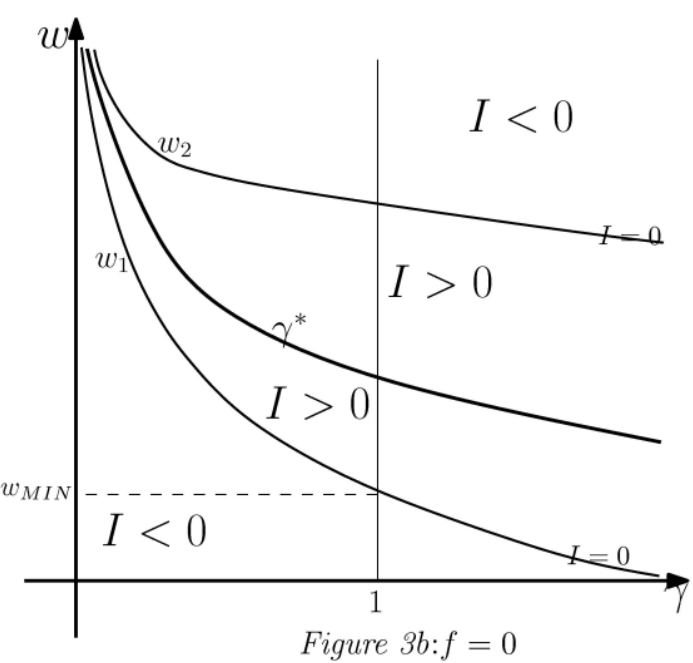

Figure $3 b: f=0$

Figure 3: The optimal rate of contribution and the incentive function

From the pictures above, first, we can see that the $\gamma^{*}$ locus is always above the $w_{l}$ locus while it is always below $w_{2}$ only for $f=0$. Second, we observe that below a certain wage ( $w_{M I N}$ in the figure) only a $\gamma$ above 1 would induce a worker to choose the risky plan. This value of wages (which is obtained inserting $\gamma=1$ in the equation of $w_{l}$ ) defines a threshold: workers whose wage is below $w_{M I N}$ will not opt for the risky plan even with the adoption of an adequate (feasible) rate of compulsory contribution. Hence we can summarize our finding in the following:

\footnotetext{
${ }^{15}$ Note that the curve $\gamma^{*}$ is necessarily above curve $w_{1}$ and, for $f>0$, it meets curve $w_{2}$ at its vertex. Moreover both curves are drawn under the assumption that $\frac{1}{2} \frac{\left(\bar{r}-r_{s}\right)^{2}}{2 a \sigma^{2} x}>F$ because, when this condition is not met, the problem becomes trivial and the incentive $I$ is always negative.
} 
REMARK 1 TO PROPOSITION 3

For workers below a certain wage, no feasible contribution rate can induce individuals to adhere to the risky

plan. The value $w_{\text {MIN }}$ of that threshold is $\frac{\bar{r}-r_{s}-f \cdot x-\sqrt{\left(\bar{r}-r_{s}-f \cdot x\right)^{2}-2 a \sigma^{2} F x}}{a \sigma^{2}}$.

\section{An extended model: decreasing risk Aversion and endogenous financial Literacy}

We enrich now our analysis by exploring the possibility that risk aversion is decreasing in income and that financial literacy of individuals is endogenously chosen ${ }^{17}$. In what follows we focus mainly on the case $f>0$ because, when $f$ is equal to zero the results remain qualitatively the same as in the previous sections.

\subsection{Decreasing risk aversion}

The analysis we built in previous sections adopted a CARA utility function. This implies that individuals' risk aversion does not depend on individuals' income or wealth. This assumption has been challenged by a number of empirical works (see for example Vissing-Jorgensen 2002). To reconcile our theoretical model with this empirical evidence we adopt now the approach suggested by Makarov and Schornick (2010) which consists in directly making the absolute-risk aversion parameter wealth-dependent. This approach allows us to maintain the CARA utility function which is necessary to keep the problem analytically tractable and to reconcile our findings with the evidence of empirical works.

We proceed then to assume the existence of a clean-cut negative relationship between wage and the absolute risk aversion coefficient: this implies that wealthier individuals display lower absolute risk aversion (a feature that is thus common with the CRRA setup). In particular we assume that the exact relationship is given by

$$
a=k \cdot w^{-\alpha}
$$

\footnotetext{
${ }^{16}$ However, we should stress that the decentralized solution would not necessarily be socially optimal, as it could entail, for example, extra costs associated with moral hazard behaviour and a likely increase in the costs related to the higher degree of complexity of the decision on the optimal rate of contribution that individuals would face in this case.

${ }^{17}$ The development of this latter aspect was suggested by a referee: we are grateful for this useful suggestion.
} 
where $\alpha \geq 0$ is a parameter that measures the elasticity of the risk aversion parameter with respect to income and $k>0$ is simply a scale factor. In particular, for any $\alpha>0$, we observe decreasing absolute risk aversion with respect to income, so that this formulation allows us to treat what is considered to be the most realistic case $^{18}$. Similarly, $\alpha$ determines the behaviour of relative risk aversion with respect to income: relative risk aversion is increasing for $0<\alpha<1$, constant for $\alpha=1$ and decreasing for $\alpha>1$. Note that for $\alpha=0$ we have $a=k$ so that risk aversion and income are unrelated and, thus, we obtain the case we treated in previous sections. Although we provide here a general analysis, non-decreasing relative risk aversion is probably the most realistic assumption and, consequently, $\alpha \geq 1$ describes the most realistic case.

\subsection{Endogenous financial literacy}

The other aspect we want to explore in more details concerns the nature of the information costs to participate to the more complex plan $R$. In fact those costs should depend on the individuals' degree of knowledge in the finance field, something which is usually called financial literacy. Moreover, it is possible that individuals can directly invest in the formation of financial literacy so that the degree of knowledge is optimally chosen to abate the costs in question. In other words, the level of financial literacy and the costs to access to the plan $R$ can be considered endogenous. We will see that these new assumptions will allow to increase the degree of realism of our model and to obtain results that are more in line with empirical evidence, although at the cost higher formal complexity.

To include these aspects within our model, we imagine that during the first period individuals can make an investment to acquire financial literacy and that the level of literacy acquired reduces the costs to access the more complex plan $R$. We assume that individuals that invest a real amount $T$ obtain financial literacy $L$ according to following production function:

$$
L=T^{\delta}
$$

where $\delta<1$ is the elasticity of financial literacy with respect to investment.

The acquisition of an amount $L$ of financial literacy reduces the costs to access the complex plan $R$ and in particular we assume that information costs $C_{R}$ are now described by

$$
C_{R}=\frac{F+f w}{L}
$$

The cost to access plan $R$ is still made up by a fixed cost $F$ and by an opportunity cost $f w$ but they are reduced by the amount of financial literacy $L$. Within this framework, an individual that chooses the plan $R$ has to pay the above cost plus the (desired) amount invested to obtain financial literacy. Exploiting eqs. (16) and (17) we obtain the total cost $D_{R}$ to enter plan $R$ :

$$
D_{R}=\frac{F+f w}{T^{\delta}}+T
$$

In addition, we allow $T$ to be chosen optimally. In practice, individuals invest in the acquisition of financial literacy the optimal amount $T^{*}$ (which implies an optimal amount of literacy $L^{*}$ ) that minimizes the above cost, therefore:

$$
T^{*}=\underset{T}{\arg \min }\left(\frac{F+f w}{T^{\delta}}+T\right)
$$

Solving the above we obtain the optimal level of literacy:

$$
L^{*}=[\delta(F+f w)] \frac{\delta}{1+\delta}
$$

\footnotetext{
${ }^{18}$ See for example Mas-Colell et al. (1995), chapter 6.
} 
which is an increasing function of wage. Given eq. (20), the actual total cost to access plan $R$ is now given by

$$
D_{R}^{*}=\Delta(F+f w)^{\frac{1}{1+\delta}}
$$

where $\Delta \equiv \delta^{\frac{1}{1+\delta}}+\delta^{-\frac{\delta}{1+\delta}}$ and where $D_{R}^{*}$ is the actual total cost to access plan $R$ when financial literacy is optimally chosen.

We have to stress that, within this framework, the acquisition of $L^{*}$ only takes place if individuals end up choosing the risky plan $R$. On the contrary, if the safe plan is preferred, no investment in literacy is required and $L^{*}$ becomes zero. From this point of view we could interpret $L^{*}$ as the acquisition of literacy that is incremental to some basic knowledge that individuals have. Therefore, we are not actually suggesting that individuals that choose the safe plan have necessarily zero literacy but, rather, that they do not acquire any extra literacy on top of their starting endowment.

\subsection{The determinants of the choice}

These new assumptions do not change the framework of our analysis but they affect some of the results. In particular eq. (10) is still correct and thus Proposition 1 is still true (so that workers still opt for the risky plan whenever $d_{R}>0$ ). However the costs to access plan $R$ are now given by eq. (21) and, consequently, the equation for $d_{R}$ can now be written as

$$
d_{R}=\gamma \frac{\bar{r}-r_{s}-\gamma \cdot k \cdot w^{1-\alpha} \cdot \sigma_{R}^{2} / 2}{x}-\frac{D_{R}^{*}}{w}=\Omega-\Phi w^{1-\alpha}-\Delta \frac{(F+f w)^{\frac{1}{1+\delta}}}{w}
$$

where $\Omega \equiv \gamma \frac{\bar{r}-r_{s}}{x}>0$ and $\Phi \equiv \frac{\gamma^{2} \cdot k \cdot \sigma_{R}^{2} / 2}{x}>0$.

\subsection{The role of wages}

The relationship between wage and the incentive to opt for the risky plan is now somehow different from the one described by eq. (9) and, starting from eq. (22), can be fully described by the following equations:

$$
\forall \alpha, \lim _{w \rightarrow 0} d_{R}=-\infty<0
$$

that is, for wages low enough, individuals do not opt for the risky plan;

$$
\begin{cases}\text { for } 0 \leq \alpha<1 & \lim _{w \rightarrow \infty} d_{R}<0 \\ \text { for } \alpha \geq 1 & \lim _{w \rightarrow \infty} d_{R}>0\end{cases}
$$

that is, for $0 \leq \alpha<1$, for wages large enough, the incentive to opt for the risky plan is negative, while for $\alpha \geq 1$, for wages large enough, the incentive to opt for the risky plan is positive. Furthermore, one gets (see Appendix B):

$$
\alpha \geq 1 \Rightarrow \partial d_{R} / \partial w>0 \forall w
$$

that is, taking into account eqs. (23), (24) and (25) we have that, for $\alpha \geq 1$, the incentive starts negative and it increases monotonically until it eventually becomes positive. Basically, low income workers opt for the safe plan, but above a certain wage threshold, all workers choose the risky option.

Some other, more complicated, properties can be also derived for $0 \leq \alpha<1$. In fact we obtain:

$$
\forall 0 \leq \alpha<1,\left.\frac{\partial d_{R}}{\partial w}\right|_{w=0}>0
$$

and 


$$
\forall 0 \leq \alpha<1, \frac{\partial d_{R}}{\partial w}>0 \Rightarrow \frac{\partial^{2} d_{R}}{\partial w^{2}}<0 \text {. }
$$

The proofs of (26) and (27) are provided in Appendix B. Considering (23), (24), (26) and (27) we have that, for $0 \leq \alpha<1$ the incentive starts and ends negative and it has an inverted $\mathrm{U}$-shape pattern (becoming positive at some point if and only if $\max _{w} d_{R}>0$ ).

We can summarize the above findings through the following proposition:

\section{PROPOSITION 4}

There exists an income threshold $w_{1}$ below which no individual opts for the risky plan. Moreover:

a) for $0 \leq \alpha<1$ and $\max _{R} \leq 0$, no individual chooses the risky plan;

b) for $0 \leq \alpha<1$ and $\max _{w} d_{R}>0$, individuals whose wage $w$ falls within the interval $\left(w_{1}, w_{2}\right)$ chooses the risky plan while the rest choose the safe plan;

c) for $\alpha \geq 1$, individuals whose wage $w$ is above $w_{1}$ choose the risky plan.

The graph below describes the pattern of $d_{R}$ (and thus of the sign of the incentive) with respect to wages.

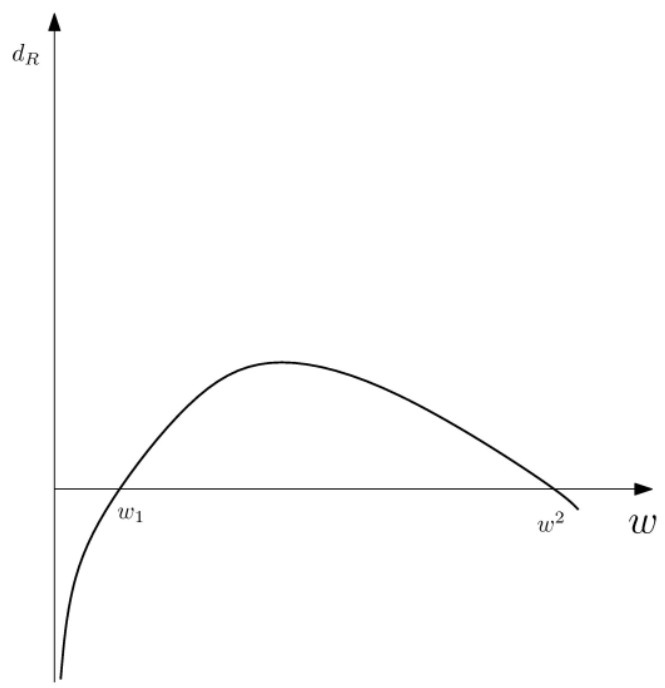

Figure $4 a: 0 \leq \alpha<1$

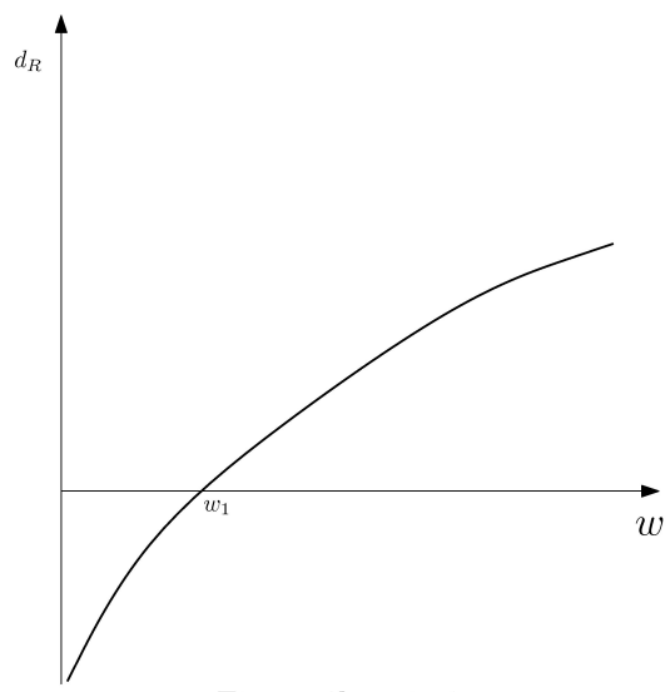

Figure $4 b: \alpha \geq 1$

Figure 4: The incentive to adhere to the risky plan in relation to wages

To sum up, we can conclude that, for $0 \leq \alpha<1$, the relationship between wages and adhesion to the risky plan is qualitatively the same as the one we obtained in section 4 . On the contrary when $\alpha \geq 1$ things change dramatically, in that there exists a unique threshold $w_{1}$ above which individuals choose the safe plan. This is due to the fact that, when income increases, the decrease in risk aversion more than compensates the increase in volatility, so that the risky plan becomes more attractive. Endogenous literacy also has a role, de facto reducing the cost to access the risky plan and making the latter more attractive. More precisely, given the endogeneity of financial literacy, the cost to access the risky plan becomes relatively smaller for higher income individuals.

\subsection{The optimal contribution rate}

We examine now the relationship between the compulsory contribution rate and the incentive to opt for the risky plan. This analysis allows us also to derive the optimal contribution rate in a context where absolute risk aversion is decreasing in income and where financial literacy is endogenously determined.

Since Proposition 1 still holds under these new assumptions, we know that decisions of individuals are determined by the sign of $d_{R}$. However, $d_{R}$ is now described by eq. (22) and thus we can exploit the latter equation to formulate a new proposition on the value of the optimal contribution rate: 
PROPOSITION 5

There exists a value $\gamma^{*}$ which maximises the expected utility of individuals. Such value maximises the value of $d_{R}$ and of I and is given by $\gamma^{*}=\frac{\bar{r}-r_{s}}{k w^{1-\alpha} \sigma^{2}}$.

We can also characterize the relationships between optimal rates and wages as follows:

\section{REMARK 1 TO PROPOSITION 5}

For $0 \leq \alpha<1$, the optimal contribution rate is decreasing in wages; for $\alpha>1$, is increasing in wages; for $\alpha=1$, the optimal rate is the same for all wages.

Differently from Proposition 3, the normative prescriptions do not imply a flat contribution, in that the optimal rate depends on the value of $\alpha$ and it is actually decreasing/constant/increasing depending on whether relative risk aversion is decreasing/constant/increasing respectively.

Moreover, the optimal rate is not affected directly by the costs to access the risky scheme or by the costs to obtain financial literacy. However, it is important to stress that these costs, although not entering the formula of the optimal contribution rate, are crucial in determining whether, once contribution has been set at its optimal level, individuals will choose the safe or the risky scheme.

Finally, we explore what happens to individuals' choices when contribution rate is set at its optimal level. Inserting the optimal rate of contribution (from Proposition 5) in (22) we obtain

$$
d_{R}\left(\gamma^{*}\right)=\frac{\left(\bar{r}-r_{s}\right)^{2}}{2 x k \sigma_{R}{ }^{2}} \frac{1}{w^{1-\alpha}}-\Delta \frac{(F+f w)^{\frac{1}{1+\delta}}}{w}=\left[\Psi-\Delta(F+f w)^{\frac{1}{1+\delta}} w^{-\alpha}\right] w^{\alpha-1}
$$

where $\Psi \equiv \frac{\left(\bar{r}-r_{s}\right)^{2}}{2 x k \sigma_{R}^{2}}>0$.

According to eq. (28) we obtain a new relationship between the incentive to opt for the risky plan and the wage level. In particular, the characteristics of this relationship depend on the value of the parameter $\alpha$ and we can summarize them with the following proposition:

\section{PROPOSITION 6}

Once the compulsory contribution rate is set at its optimal rate, there exists an income threshold $w_{\text {MIN }}$ below which no individual opts for the risky plan. Moreover, by defining $\Gamma=\Psi-[1-\alpha(1+\delta)]^{\alpha-\frac{1}{1+\delta}} \Delta f^{\alpha} F^{\frac{1}{1+\delta}-\alpha}$ we have

a) for $0 \leq \alpha<1 /(1+\delta) \leq$ and $\Gamma<0$, no individual chooses the risky plan;

b) for $0 \leq \alpha<1 /(1+\delta) \leq$ and $\Gamma \geq 0$, individuals whose income $w$ falls within the interval $\left(w_{M I N}, w^{M A X}\right)$ choose the risky plan while the rest choose the safe plan;

c) for $\alpha \geq 1 /(1+\delta)$, individuals whose wage is above $w_{\text {MIN }}$ choose the risky plan.

\section{PROOF see Appendix C.}

In words, the above proposition states that $d_{R}\left(\gamma^{*}\right)$ can assume different patterns ${ }^{19}$ depending on the value of $\alpha$ and that, according to it, different partitions of the population emerge. However, for any value of $\alpha$, even when the contribution rate is optimally set, there exists an income threshold below which individuals do not opt for the risky plan. The actual patterns of $d_{R}\left(\gamma^{*}\right)$ are analytically proved in Appendix C: in Figure 5, for illustrative purposes, we depict the different possible cases. The patterns drawn in the figure determine the sign of the incentive with respect to wages once the contribution rate has been set at its optimal level.

\footnotetext{
${ }^{19}$ In Proposition 6 we assumed, for the sake of exposition, that $\Psi-\Delta f>0$. When this is not true the point-value $\alpha=1 /(1+\delta)$ falls in case $a$ ) or case $b$ ) and the rest of the characterization remains exactly the same.
} 


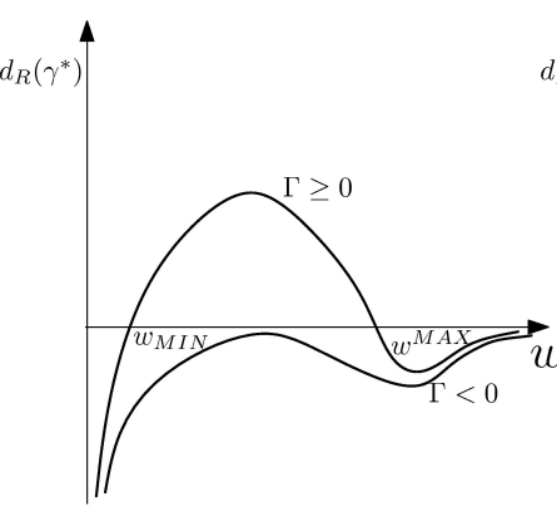

Figure 5a: $0 \leq \alpha<\frac{1}{\delta+1}$

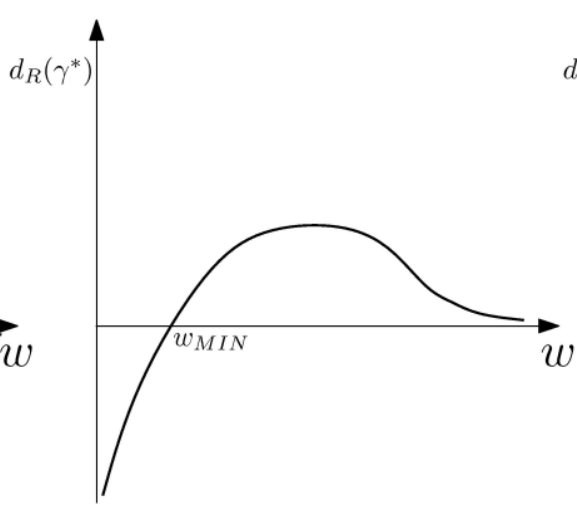

Figure $5 b: \frac{1}{\delta+1} \leq \alpha<1$

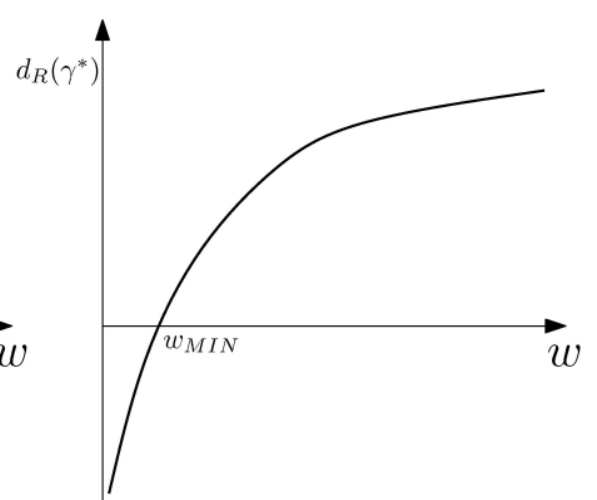

Figure 5c: $\alpha \geq 1$

Figure 5: The incentive to adhere to the risky plan in relation to wages and risk aversion when the contribution rate is set at its optimal level $\gamma^{*}$

Precisely, Figure 5a highlights how, for $0 \leq \alpha<1 /(1+\delta)$ when $\Gamma<0$ no individual chooses the risky plan while, when $\Gamma \geq 0$, individuals inside the interval $\left(w_{M I N}, w^{M A X}\right)$ opt for the risky plan while outside the interval they opt for the safe one. In this case, the parameter $\Gamma$ determines the necessary conditions for the risky plan to be attractive for at least some wage level. Differently from this first case, as it is possible to see from Figure $5 \mathrm{~b}$ and Figure $5 \mathrm{c}$, for $\alpha \geq 1 /(1+\delta)$ there is a wage threshold $w_{M I N}$ above which individuals opt for the risky plan.

These results clearly highlight the role that risk aversion has on the decision of high income individuals: the economic rationale behind the decision of this category of individuals rests in the fact that their higher income increases at the same time their risk tolerance and the volatility of their risky investment; therefore, they choose the risky plan if the former effect off-sets the latter. From this point of view, it is worth to stress that non-increasing relative risk aversion is the most realistic case and, therefore, we can conclude that the existence of a unique wage threshold $\left(w_{M I N}\right)$ is the most realistic outcome.

\subsection{The role of financial literacy and information costs}

We conclude this section by commenting on the role that financial literacy and the costs to access the more complex investment plan have within our model. We can summarize our findings in four main points.

First, within our framework the investment in financial literacy is made if and only if plan $R$ is chosen: then, the actual level of literacy acquired is given by eq. (20) when $d_{R}>0$ and is zero otherwise. As specified above, such a finding can be interpreted by recalling that the optimal level of literacy $L^{*}$ is incremental to some basic knowledge with which individuals are endowed. Consequently, our result does not imply necessarily that individuals that choose the safe plan have no financial literacy at all but, rather, that they do not find it convenient to invest in the acquisition of extra amount of literacy.

Second, higher income individuals have higher financial literacy. This happens for two reasons: $i$ ) from eq. (20), we know that literacy is directly increasing in wages and this is due to the fact that literacy abates the opportunity costs component and thus, investing in literacy is more useful for higher income individuals; ii) in the most realistic cases (i.e. $\alpha \geq 1 /(1+\delta)$ ), higher income individuals are more likely to opt for the risky plan and, consequently, they are more likely to actually invest in literacy. A similar reasoning can be applied to the parameter that measures the returns of the investment in terms of literacy so that optimal literacy is increasing in $\delta$.

Third, from eq. (22) we have that the cost parameters $F$ and $f$ strictly reduce, even in the presence of endogenous literacy, the value $d_{R}$ and thus they effectively influence the individuals' investment decision. From this point of view, higher costs, other things equal, also increase the value $w_{M I N}$ and decreases the value $w^{M A X}$ de facto reducing the share of population that opts for the risky plan. Moreover, even if the information costs do not affect the optimal rate of contribution $\gamma^{*}$, they still affect negatively $d_{R}\left(\gamma^{*}\right)$ and, therefore, they are still fundamental in determining individuals' choice even when contribution rate is optimally set. 


\section{Conclusions}

In this paper we tackle the issue of retirement saving both from a positive and normative point of view. At the heart of this paper there is the study of the new trend according to which pension systems provide more freedom of choice for workers in terms of different portfolio options. The other side of the coin of such increased freedom to choose is higher individual responsibility and higher request/costs for information and financial literacy.

Here we analyse the mechanisms behind the retirement saving choice, concerning both the amount and the investment decision, and we build a model able to represent this process and assess its determinants in presence of stochastic returns, information costs and financial literacy. More precisely, our analysis highlights how the choice is influenced, besides the economic attractiveness of the plans, by three relevant factors: 1) the level of wages; 2) the rate of the mandatory contribution; 3) risk aversion. In particular we show that at the aggregate level it may emerge a partition of the population in adhesions to riskier pension plans that is based on the income level of workers. From this point of view, the fact that information costs prevent low-income individuals from acquiring information, financial literacy and, consequently, from adhering to riskier schemes emerges as a robust result. As for higher income individuals, we show that the incentive function to diversify the investment for retirement savings depends crucially on risk aversion, and in particular non-increasing relative risk aversion is sufficient to obtain results that are in line with consolidated empirical findings, according to which higher income individuals invest relatively more in risky assets.

As for the contribution rate, we prove the existence of a socially optimal value and we show that it is shaped, among other things, by the exact relationship between income and risk aversion. These results are robust even in that they emerge even in the presence of endogenous financial literacy.

Finally, some policy implications can be drawn from our analysis. In fact, our model suggests that the choice of individuals may be driven not only by their personal preferences (i.e. risk aversion) but also by their income level and by the lack of financial literacy. Since these latter elements may reduce the freedom of choice, a benevolent authority might desire to intervene to remove or mitigate those barriers that appear to burden in particular low income individuals.

Clearly, the setting of an optimal rate of contribution is a first step in this direction but we also showed that even in this case individuals' endowments can affect the possibility to diversify retirement-savings portfolio, in that the barrier generated by the need to pay information costs to assess riskier assets is in general insurmountable for low-income workers.

Thus, if authorities aim at promoting freedom of choice for all workers, a more direct intervention is needed. According to our model this would imply actions that affect the wage thresholds, which can be achieved through at least three possible actions: 1) fiscal incentives for workers opting for the risky scheme; 2) a lump sum benefit for workers opting for the risky scheme; 3 ) information campaigns and/or campaigns aimed at increasing financial literacy. These three actions could actually be implemented either for all workers or only for those categories that are in the need of incentives to adhere: clearly the latter solution requires fewer resources but might involve some drawbacks in terms of the fairness of the intervention and of the fact that it may be difficult to restrict the intervention only to those that actually need it.

\section{References}

Benedict, M. and Shaw, K., 1995, The impact of pension benefits on the distribution of earned income, Industrial and Labor Relations Review, Vol. 48(4), pp. 740-757.

Bertaut, C. C, Haliassos, M., 1995, Why Do So Few Hold Stocks? Economic Journal, 105(432), pp. 11101129. 
Blake, D., 2006, Pension Economics, John Wiley \& Sons.

2 Christiansen, C., Joensen, J.S. and Rangvid J., "Are economists more likely to hold stocks?",2008, Review of Finance", 12(3), pp. 465-496.

Clark, R. L., McDermed, A., Sawant K. and D'Ambrosio, M.A., 2003, Financial education and retirement savings, Proceedings, Board of Governors of the Federal Reserve System (U.S.).

Corsini, L., Pacini, P. M. and Spataro, L., 2012, Workers' Choice on Pension Schemes: a Theoretical Model and an Application to the Italian Second Pillar Reform, Public Finance Review,vol. 40(2), pp 207-239.

Corsini, L., and Spataro, L., 2013, Savings for retirement under liquidity constraints: a note, Economics Letters, 118 (2), 258-261.

Creedy, J., 1994, Two-tier state pensions: Labour supply and income distribution, The Manchester School of Economic \& Social Studies, vol. 62(2), pp. 167-183.

D'Amato, M. and Galasso, V., (2010), Political intergenerational risk sharing, Journal of Public Economics, Vol. 94, pp. 628-637.

Demange, G., 2009, On sustainable Pay As You Go contribution rules, Journal of Public Economic Theory, Vol. 4 (8), pp. 493-527.

De Menil, G., Murtin, F. and Sheshinski, E., 2006, "Planning for the optimal mix of paygo tax and funded savings," Journal of Pension Economics and Finance, vol. 5(01), pp. 1-25.

Dutta, J., Kapur, S. and Orszag, J. M., 2000, A portfolio approach to the optimal funding of pensions, Economics Letters, vol. 69(2), pp. 201-206.

Fornero, E. and Monticone, C., 2011, Financial literacy and pension plan participation in Italy, Journal of Pension Economics and Finance, 10(04), pp. 547-564.

Gordon, R. and Varian, H., 1988, Intergenerational risk sharing. Journal of Public Economics, Vol. 37, pp. 185-202.

Guiso, L. and Paiella, M., 2006, Risk aversion, wealth and background risk, Journal of the European Economic Association, vol. 6(06), pp. 1109-1150.

Iyengar, S.S., Jiang, W. and Huberman, G, 2004, How Much Choice is Too Much?: Contributions to 401(k) Retirement Plans, in Pension Design and Structure: New Lessons from Behavioral Finance, Ed. by Olivia S. Mitchell and Stephen P. Utkus. Oxford: Oxford University Press.

Jappelli, T. and Padula, M., 2011, Investment in Financial Literacy and Saving Decisions, CEPR Discussion Papers 8220, Centre for Economic Policy Research.

Lusardi, A. and Mitchel, O. S., 2009, How Ordinary Consumers Make Complex Economic Decisions: Financial Literacy and Retirement Readiness, NBER Working Papers 15350, National Bureau of Economic Research, Inc.

Lusardi, A. and Mitchel, O. S., 2011, Financial Literacy and Retirement Planning in the United States, Journal of Pension Economics and Finance, 10(04), pp. 509-525.

Lusardi A., Michaud, P. and Mitchell, O. S., 2011, "Optimal Financial Literacy and Saving for Retirement," Working Papers 905, RAND Corporation Publications Department.

Makarov, D. and Schornick, A. V., 2010, A note on wealth effect under CARA utility, Finance Research Letters, Vol. 7(3), pp. 170-177.

Mas-Colell, A., Whinsthon, M. D. and Green, J. R., 1995, Microeconomic Theory, Oxford University Press.

Maurer, R., Mitchell, O. S. and Rogalla, R., 2010, The Effect of Uncertain Labor Income and Social Security on Life-cycle Portfolios, NBER Working Papers 15682, National Bureau of Economic Research, Inc.

Matsen E. and Thogersen, O., 2004, Designing social security - a portfolio choice approach, European Economic Review, vol. 48(4), pp. 883-904.

Merton, R. C., 1969, Lifetime Portfolio Selection under Uncertainty: The Continuous-Time Case, The Review of Economics and Statistics, Vol. 51(3), pp. 247-257.

OECD 2005, Improving Financial Literacy, OECD Publishing.

OECD 2011, Pension at a glance, OECD Publishing.

Phelps, E. S, 1962, The Accumulation of Risky Capital: A Sequential Utility Analysis, Econometrica, Vol. 30(4), pp. 729-43.

Samuelson, P.A., 1958, An Exact Consumption-Loan Model of Interest with or without the Social Contrivance of Money, Journal of Political Economy, Vol. 66, pp 467-482.

Samuelson, P.A., 1969, Lifetime Portfolio Selection by Dynamic Stochastic Programming, The Review of Economics and Statistics, Vol. 51(3), pp. 239-246.

Samuelson, P.A., 1975, Optimum Social Security in a Life-Cycle Growth Model, International Economic Review, Department of Economics, Vol. 16(3), pp. 539-544. 
SSA (2010a), Social Security Programs Throughout the World: Europe, 2010, SSA Publication No. 1311801.

SSA (2010b), Social Security Programs Throughout the World: The Americas, 2009, SSA Publication No. 13-11804.

Varian, H. R., 1992, Microeconomic Analysis, New York : Norton.

van Rooij, M., Lusardi, A. and Alessie, R, 2011, "Financial literacy and stock market participation", Journal of Financial Economics, 101(2), pp. 449-472.

Veall, M. R., 1986, Public pensions as optimal social contracts, Journal of Public Economics, vol. 31(2), pp. 237-251.

Vissing-Jorgensen, A., 2002, Limited asset market participation and the elasticity of intertemporal substitution, Journal of Political Economics Vol. 110, pp. 825-853.

Wagener, A., 2003, Pensions as a portfolio problem: fixed contribution rates vs. fixed replacement rates reconsidered, Journal of Population Economics, Vol. 16(1), pp. 111-134.

\section{APPENDIX A}

The optimal consumption in period 1 and period 2 is obtained solving the following maximization problem:

$$
\left\{\begin{array}{l}
\max _{c_{1}}-e^{-a c_{1}}-\rho e^{-a\left(\bar{c}_{2}-a \sigma_{c_{2}}^{2} / 2\right)} \\
\text { s.t. } c_{2} \sim N\left[\left(w-c_{1}-C_{i}\right)(1+r)+\gamma w\left(\bar{r}_{i}-r\right), \gamma^{2} w^{2} \sigma_{i}^{2}\right] . \\
\text { s.t. } c_{1}, E\left(c_{2}\right) \geq 0
\end{array}\right.
$$

The above can be written as

$$
\max _{c_{1}}-e^{-a c_{1}}-\rho e^{-a\left[\left(w-c_{1}-c_{i}\right)(1+r)+w\left(\bar{r}_{i}-r\right)-a \gamma^{2} w^{2} \sigma_{i}{ }^{2} / 2\right]}
$$

and consequently, the optimal value of consumption $c_{1, i}^{*}$ is the value of $c_{1}$ for which

$$
\frac{\partial\left\{-e^{-a c_{1}}-\rho e^{-a\left[\left(w-c_{1}-C_{i}\right)(1+r)+w\left(\bar{r}_{i}-r\right)-a \gamma^{2} w^{2} \sigma_{i}^{2} / 2\right]}\right\}}{\partial c_{1}}=0 .
$$

Eq. (A3) implies

$$
a e^{-a c_{1}}-a(1+r) \rho e^{-a\left[\left(w-c_{1}-C_{i}\right)(1+r)+w\left(\bar{r}_{i}-r\right)-a \gamma^{2} w^{2} \sigma_{i}^{2} / 2\right]}=0
$$

or, equivalently

$$
e^{-a c_{1}}=x \rho e^{-a\left[\left(w-c_{1}-C_{i}\right)(1+r)+w\left(\bar{r}_{i}-r\right)-a \gamma^{2} w^{2} \sigma_{i}^{2} / 2\right]}
$$

where $x=(1+r)$. Before to proceed, through algebraic manipulation it is easy to see that

$$
\left(w-c_{1}-C_{i}\right) x+\gamma w\left(\bar{r}_{i}-r\right)-a \gamma^{2} w^{2} \sigma_{i}^{2} / 2=\left[1+\gamma \frac{\left(\bar{r}_{i}-r\right)-a x w \sigma_{i}^{2} / 2}{x}-\frac{C_{i}}{w} \mid x w-x c_{1} .\right.
$$

Therefore, if we define $d_{i}=\gamma \frac{-\left(\bar{r}_{i}-r\right)-a p w \sigma_{i}^{2} / 2}{x}-\frac{C_{i}}{w}$, we can insert (A6) into (A5) to obtain

$$
e^{-a c_{1}}=x \rho e^{-a\left[\left(1+d_{i}\right) w-c_{1}\right] x}
$$

Solving the above with respect to $c_{l}$ we have (taking logs of both sides of the equation): 


$$
-a c_{1}=\log (1+r) \rho-a\left[\left(1+d_{i}\right) w-c_{1}\right] x
$$

that finally delivers:

$$
c_{1, i}^{*}=\left[\left(1+d_{i}\right) w x-\frac{\log \rho x}{a}\right] \frac{1}{(1+x)} .
$$

Once obtained the above, it is easy to compute also the value $c_{2, i}^{*}$ and $E\left(U_{i}^{*}\right)$ inserting eq. (A9) into eqs. (1) and (3) respectively.

\section{APPENDIX B}

16 We want to prove here the following points:

i) $\quad \alpha \geq 1 \Rightarrow \partial d_{R} / \partial w>0 \forall w$.

ii) $\quad \forall 0 \leq \alpha<1,\left.\frac{\partial d_{R}}{\partial w}\right|_{w=0}>0$.

iii) $\quad \forall 0 \leq \alpha<1, \frac{\partial d_{R}}{\partial w}>0 \Rightarrow \frac{\partial^{2} d_{R}}{\partial w^{2}}<0$

$g(w)=\frac{F}{w^{1+\delta}}+\frac{f}{w^{\delta}}$

so that $g(w)>0$ and

$24 \quad \frac{\partial g(w)}{\partial w}=-(1+\delta) \frac{F}{w^{2+\delta}}-\delta \frac{f}{w^{1+\delta}}<0$.

25 From equation (22) we know that $d_{R}=\Omega-\Phi w^{1-\alpha}-\Delta \frac{(F+f w)^{\frac{1}{1+\delta}}}{w}$ and thus:

$$
\frac{\partial d_{R}}{\partial w}=-\Phi(1-\alpha) w^{-\alpha}-\Delta \frac{\partial g(w)}{\partial w}[g(w)]^{-\frac{\delta}{1+\delta}} \text {. }
$$

\section{Proof of Point i.}

For $\alpha \geq 1$, the first addend of eq. (B3) in non-negative and the second, given (B2), is positive: then,

\section{Proof of Point ii.}

33 We can rearrange equation (B3) as

$34 \frac{\partial d_{R}}{\partial w}=\left[-\Phi(1-\alpha) w^{1-\alpha}-\Delta \frac{\partial g(w)}{\partial w} w[g(w)]^{-\frac{\delta}{1+\delta}}\right] \frac{1}{w}$ and combining the above with eqs. (B1) and (B2) we obtain:

$$
\frac{\partial d_{R}}{\partial w}=\left[-\Phi(1-\alpha) w^{1-\alpha}+\Delta\left[(1+\delta) \frac{F}{w^{1+\delta}}+\delta \frac{f}{w^{\delta}}\right]\left(\frac{F}{w^{1+\delta}}+\frac{f}{w^{\delta}}\right)^{-\frac{\delta}{1+\delta}}\right] \frac{1}{w}
$$
and rearranging the above 
$1 \quad \frac{\partial d_{R}}{\partial w}=\left[-\Phi(1-\alpha) w^{1-\alpha}+\Delta F\left(\frac{1}{w^{1+\delta}}\right)^{\frac{1}{1+\delta}}(F+f w)^{-\frac{\delta}{1+\delta}}+\Delta\left(\frac{F}{w^{1+\delta}}+\frac{f}{w^{\delta}}\right)^{\frac{1}{1+\delta}}\right] \frac{1}{w}$

2 which, for $w=0$ and $0 \leq \alpha<1$, is strictly positive.

Proof of Point iii.

Preliminarily we define

$7 \quad b(w)=-\Delta \frac{\partial g(w)}{\partial w} w^{\alpha} \frac{1}{1+\delta} g(w)^{-\frac{\delta}{1+\delta}}$.

8 Note that from (B2) we have $b(w)>0$.

9 Exploiting eq. (B1) and (B2) we can rearrange (B5) as

$11 b(w)=\Delta\left[(1+\delta) \frac{F}{w^{2+\delta}}+\delta \frac{f}{w^{1+\delta}}\right] w^{\alpha} \frac{1}{1+\delta}\left(\frac{F}{w^{1+\delta}}+\delta \frac{f}{w^{\delta}}\right)^{-\frac{\delta}{1+\delta}}$

12 and, going through computation we obtain

$b(w)=\Delta\left[(1+\delta) \frac{F}{w}+\delta f\right] w^{\alpha} \frac{1}{w^{1+\delta}} \frac{1}{1+\delta}\left(\frac{1}{w^{1+\delta}}\right)^{-\frac{\delta}{1+\delta}}(f+\delta w)^{-\frac{\delta}{1+\delta}}$

14 which finally yields

$b(w)=\Delta \frac{1}{1+\delta}\left[(1+\delta) \frac{F}{w}+\delta f\right] w^{\alpha-1} \frac{1}{1+\delta}(f+\delta w)^{-\frac{\delta}{1+\delta}}$.

16 Given that $(1+\delta) \frac{F}{w}+\delta f, w^{\alpha-1}$ and $(f+\delta w)^{-\frac{\delta}{1+\delta}}$ are positive and decreasing in $w$, from eq. (B5c) we have:

$17 \quad \frac{\partial b(w)}{\partial w}<0$.

18 We also define

19

$h(w)=-\Phi(1-\alpha)-\Delta \frac{\partial g(w)}{\partial w} w^{\alpha} \frac{1}{1+\delta}[g(w)]^{-\frac{\delta}{1+\delta}}=-\Phi(1-\alpha)+b(w)$

20 Note that $\partial h(w) / \partial w=\partial b(w) / \partial w$ and thus, for $\alpha<1$ :

$21 \quad \frac{\partial h(w)}{\partial w}<0$.

Combining eq. (B4) and eq. (B7) we have

$23 \quad \frac{\partial d_{R}}{\partial w}=h(w) w^{-\alpha}$

24 and thus:

25

$\frac{\partial^{2} d_{R}}{\partial w^{2}}=\frac{\partial h(w)}{\partial w} w^{-\alpha}-\alpha h(w) w^{-\alpha-1}$.

26 From (B9) we necessarily have that $\frac{\partial d_{R}}{\partial w}>0 \Rightarrow h(w)$ and from (B6) we have that, for $\alpha<1, \frac{\partial h(w)}{\partial w}<0$ : therefore (B10) implies that $\forall 0 \leq \alpha<1, \frac{\partial d_{R}}{\partial w}>0 \Rightarrow \frac{\partial^{2} d_{R}}{\partial w^{2}}<0$.

\section{APPENDIX C}

To prove Proposition 6 we prove here that:

LEMMA 1. The following holds true:

i) $\lim _{w \rightarrow 0} d_{R}\left(\gamma^{*}\right)=-\infty<0$. 


\section{PROOF OF LEMMA 3.}

We can rearrange eq. (22) as

$$
d_{R}\left(\gamma^{*}\right)=\left[\Psi-\Delta\left(F w^{-\alpha(1+\delta)}+f w^{1-\alpha(1+\delta)}\right)^{\frac{1}{1+\delta}}\right] w^{\alpha-1} .
$$

LEMMA 2. $\forall \alpha \geq 1$ the following holds true:

$$
\text { i) } \lim _{w \rightarrow \infty} d_{R}\left(\gamma^{*}\right)>0
$$$$
\text { ii) } d_{R}\left(\gamma^{*}\right) / \partial w>0 \text {. }
$$

LEMMA 3. $\forall 1 /(1+\delta) \leq \alpha<1$ the following holds true:
i) $\forall \varepsilon>0, \forall M, \exists w>M \Rightarrow 0<d_{R}\left(\gamma^{*}\right)<\varepsilon$
ii) $d_{R}\left(\gamma^{*}\right) \leq 0 \Rightarrow \partial d_{R}\left(\gamma^{*}\right) / \partial w>0$

LEMMA 4. $\forall 0<\alpha<1 /(1+\delta)$ the following holds true:
i) $\forall \varepsilon>0, \forall M, \exists w>M:-\varepsilon<d_{R}\left(\gamma^{*}\right)<0$
ii) $\exists w: d\left(\gamma^{*}\right)>0 \Leftrightarrow \Gamma>0$
iii)For $\Gamma>0, d_{R}\left(\gamma^{*}\right)=0$ for two and only two values of $w$.

and we than show how the above lemmas prove Proposition 6 .

\section{PROOF OF LEMMA 1.}

We can rearrange eq. (22) as

$d_{R}\left(\gamma^{*}\right)=\left[\Psi w^{\alpha}-\Delta(F+f w)^{\frac{1}{1+\delta}}\right] w^{-1}$

from which we easily obtain $\lim _{w \rightarrow 0} d_{R}\left(\gamma^{*}\right)=-\infty$.

\section{PROOF OF LEMMA 2.}

We can rearrange eq. (22) as

$d_{R}\left(\gamma^{*}\right)=\Psi w^{\alpha-1}-\Delta\left(\frac{F}{w^{1+\delta}}+\frac{f}{w^{\delta}}\right)^{\frac{1}{1+\delta}}$

from which, for $\alpha \geq 1$, we easily obtain $\lim _{w \rightarrow \infty} d_{R}\left(\gamma^{*}\right)>0$ $-\Delta\left(\frac{F}{w^{1+\delta}}+\frac{f}{w} \delta\right)^{\frac{1}{1+\delta}}$ is strictly increasing in $w$. Then, $d_{R}\left(\gamma^{*}\right) / \partial w>0$

Consider the above equation. For $1 /(1+\delta) \leq \alpha<1$, it is easy to see that:

$$
\lim _{w \rightarrow \infty} d_{R}\left(\gamma^{*}\right)=0
$$

and that (for $\Psi-\Delta f>0$ ):

Consider eq. (C2): for $\alpha \geq 1$ it is easy to see that $\Psi w^{\alpha-1}$ is non-decreasing in $w$ and that 
$\lim _{w \rightarrow \infty}\left[\Psi-\Delta\left(F w^{-\alpha(1+\delta)}+f w^{1-\alpha(1+\delta)}\right)^{\frac{1}{1+\delta}}\right]>0$.

2 Obviously we have

$3 \forall M, \exists w>M: w^{\alpha-1}>0$

4 and, from (C5) we have

$5 \quad \forall M, \exists w>M:\left[\Psi-\Delta\left(F w^{-\alpha(1+\delta)}+f w^{1-\alpha(1+\delta)}\right)^{\frac{1}{1+\delta}}\right]>0$.

6 Given eq. (C3), from (C4), (C5) and (C7) we necessarily have $\forall \varepsilon>0, \forall M, \exists w>M \Rightarrow 0<d_{R}\left(\gamma^{*}\right)<\varepsilon$

7 We now define

$8 \quad m(w)=\Delta(F+f w)^{\frac{1}{1+\delta}} w^{-\alpha}$

9 and, consequently, we can rewrite eq. (22) as:

$10 \quad d_{R}\left(\gamma^{*}\right)=[\Psi-m(w)] w^{\alpha-1}$.

11 From definition (C8) we have:

$\frac{\partial m(w)}{\partial w}=-\Delta \alpha(F+f w)^{-\frac{\delta}{1+\delta}}\left[F+\left(1-\frac{1}{\alpha(1+\delta)}\right) f w\right]^{-\frac{\delta}{1+\delta}} w^{-1-\alpha}$.

13 so that

$14 \quad \forall 1 /(1+\delta) \leq \alpha<1, \partial m(w) / \partial w<0$.

15 Given equation (C9) we have

$16 \quad \frac{\partial d_{R}\left(\gamma^{*}\right)}{\partial w}=-\frac{\partial m(w)}{\partial w} w^{\alpha-1}+(\alpha-1)[\Psi-m(w)] w^{\alpha-2}$.

17 From equation (C9) we also know that $d_{R}\left(\gamma^{*}\right) \leq 0 \Leftrightarrow[\Psi-m(w)] \leq 0$ and combining this with (C11) and 18 (C12), we necessarily have that, $\forall 1 /(1+\delta) \leq \alpha<1, d_{R}\left(\gamma^{*}\right) \leq 0 \Rightarrow \partial d_{R}\left(\gamma^{*}\right) / \partial w>0$

PROOF OF LEMMA 4.

21 Consider eq. (C2): for $0<\alpha<1 /(1+\delta)$, it is easy to see that

$22 \lim _{w \rightarrow \infty} d_{R}\left(\gamma^{*}\right)=0$

23 Moreover, for $0<\alpha<1 /(1+\delta)$ :

$\lim _{w \rightarrow \infty}\left[\Psi-\Delta\left(F w^{-\alpha(1+\delta)}+f w^{1-\alpha(1+\delta)}\right)^{\frac{1}{1+\delta}}\right]<0$.

25 From (C14) we have

$\forall M, \exists w>M:\left[\Psi-\Delta\left(F w^{-\alpha(1+\delta)}+f w^{1-\alpha(1+\delta)}\right)^{\frac{1}{1+\delta}}\right]>0$.

We define now

$n(w)=\Psi-\Delta(F+f w)^{\frac{1}{1+\delta}} w^{-\alpha}$.

31 Given eq. (28) we have that

$32 \quad d_{R}\left(\gamma^{*}\right)>0 \Leftrightarrow n(w)>0$ 
and

$2 \quad d_{R}\left(\gamma^{*}\right)=0 \Leftrightarrow n(w)=0$.

3 Clearly, $n(w)$ can be positive if and only if $\max _{w} n(w)>0$. We can thus compute this latter maximum and

4 obtain:

$5 \quad \max n(w)=\Psi-[1-\alpha(1+\delta)]^{\alpha-\frac{1}{1+\delta}} \Delta f^{\alpha} F^{\frac{1}{1+\delta}-\alpha}=\Gamma$.

6 From $(\mathrm{C} 18)$ we have that

$7 \quad \exists w: n(w)>0 \Leftrightarrow \Gamma>0$

8 and considering (C17) and (C19) we have that $\exists w: d\left(\gamma^{*}\right)>0 \Leftrightarrow \Gamma>0$.

9 Given definition (C16) we have

$10 \quad \lim _{w \rightarrow 0} n(w)=\lim _{w \rightarrow \infty} n(w)=-\infty$.

11 Consider now the case $\Gamma>0$. From $(\mathrm{C} 16)$ we have:

$\frac{\partial n(w)}{\partial w}=-\Delta\left[w-\frac{F}{f} \frac{(1+\delta) \alpha}{1-(1+\delta) \alpha}\right] \frac{1-(1+\delta) \alpha}{(1+\delta)} f\left(F w^{-\alpha(1+\delta)}+f w^{1-\alpha(1+\delta)}\right)^{\frac{-\delta}{1+\delta}} w^{-\alpha(1+\delta)-1}$.

13 Given eq. (C21), the derivative of $n(w)$ is increasing for $w<\frac{F}{f} \frac{(1+\delta) \alpha}{1-(1+\delta) \alpha}$ and decreasing thereafter:

14 combining this result with $(\mathrm{C} 19)$ and $(\mathrm{C} 20)$ we necessarily have that, for $\Gamma>0, n(w)$ is zero for two and 15 only two values of $w$ and then, from (C17a), $d\left(\gamma^{*}\right)$ is zero for two and only two values of $w$.

\section{PROOF of PROPOSITION 6}

From Lemma 1, when wage $w$ is below a certain threshold, we necessarily have $d_{R}\left(\gamma^{*}\right)<0$.

20 From Lemma 2 and Lemma 3, for $\alpha \geq 1 /(1+\delta)$, when wage $w$ is above a certain threshold, we necessarily 21 have $d_{R}\left(\gamma^{*}\right)>0$.

22 From Lemma 4, for $0 \leq \alpha<1 /(1+\delta)$ and $\Gamma<0$, we necessarily have $d_{R}\left(\gamma^{*}\right)<0$.

23 From Lemma 4 , for $0 \leq \alpha<1 /(1+\delta)$ and $\Gamma \geq 0$, there exists two values $w_{M I N}$ and $w^{M A X}$ for which, when 24 wage $w$ falls within the interval $\left(w_{M I N}, w^{M A X}\right)$ we have $d_{R}\left(\gamma^{*}\right)>0$ and when $w$ falls outside that interval we have $d_{R}\left(\gamma^{*}\right) \leq 0$. 